\title{
Beta and Sigma - Convergence of Productivity of NUTS 2 Regions in the (EU) Member States from the CEE Region
}

\section{Petar Peshev*, Vera Pirimova**}

\begin{abstract}
:
In this scientific paper we have examined the presence of beta and sigma-convergence of productivity in the Central and East European NUTS 2 statistical regions of the European Union member states of Bulgaria, Croatia, Czech Republic, Estonia, Hungary, Latvia, Lithuania, Poland, Romania, Slovakia, Slovenia for the period from 2000 to 2016. Applying a fixed effects panel ordinary least squares regression on real Gross domestic product per employee and Gross domestic product per employee in PPS terms, we find that a catch-up process is underway, together with a decrease of dispersion in variables under investigation, respectively beta and sigma convergence hypotheses are supported for the NUTS 2 regions in selected countries under investigation.
\end{abstract}

Keywords: productivity convergence, economic convergence, CEE NUTS 2 regions, EU regions, panel data models

JEL code: C23, O11, O47, R11

\section{Introduction}

In the last three decades the Old Continent has faced a lot of economic and social opportunities and challenges and went through a tremendous change in this direction. Countries from the region of Central and Eastern Europe (CEE) (Bulgaria; Croatia; Czech Republic; Estonia; Hungary; Latvia; Lithuania; Poland; Romania; Slovakia; Slovenia) had almost a once in a lifetime opportunity to transform their broken and outdated communist economies into modern welfare states. By joining the North Atlantic Treaty Organisation (NATO) and the European Union (EU) all the efforts and sacrifices CEE countries have made are paying off, through catching-up with the averages for the so-called Old EU members (the 15 members before the expansion from 2004). The convergence process is not even, with some of the CEE countries outpacing the growth for the other by much, nevertheless other countries, such as Bulgaria and Romania started from a much lower initial base, for example. Focusing on the NUTS (Nomenclature of Territorial Units for Statistics) 2 regions in the Central and East European countries from the EU gives a better perspective for analysing the catchup process. Despite the large emigration waves in the 1990s and in the beginning of the millennium, CEE members of the EU are comprising around $1 / 5^{\text {th }}$ of the population and the labour force in the EU evolving into a

\footnotetext{
Senior (Chief) assistant professor of Economics, UNWE, General Economics faculty, Economics department.
}

* Associate professor of Economics, UNWE, General Economics faculty, Economics department. 


\section{Articles}

major factor for overall EU economic, social, cultural and political development.

The 11 member states from the region of CEE are ever growing in importance, since their economies converge with the Old EU members. These countries comprise $1 / 5^{\text {th }}$ of the population and the labour force in the EU, however, their GDP is around $8.7 \%$ from the EU28 total for 2018 and despite rising from $5.4 \%$ from 2004 it is still under its potential. The topic of productivity convergence and broadly speaking of the economic convergence for the CEE member states is growing in importance, not only because of the potential of those countries to hold a fairer share of the total production, income and wealth in the EU, but also due the different speed of convergence. Peculiarities and discrepancies in the catchup process among the 11 member states from the CEE region are even better revealed when analysing NUTS 2 regions. The topic of CEE members of EU convergence has sparked the interest of many researchers, e.g. Szeles and Marinescu (2010), Kutan and Yigit (2009), Stattev and Raleva (2006), Matkowski and Próchniak (2004), while the topic is more generally covered in the prominent publications of Romer (1986), Barro and Sala-i-Martin (1991, 1992) and Sachs and Warner (1995).

After a brief literature review in this scientific paper we are investigating the productivity convergence of NUTS 2 regions towards the averages set by the 15 Old EU members. We employ panel econometric techniques in verifying the hypothesis that Beta $(\beta)$ and Sigma $(\sigma)$ - convergence can be identified among the NUTS 2 regions of CEE member states.

\section{Theoretical aspects of the economic convergence}

Before we continue with the review of some of the most important publications on the topic, we assume that economic convergence
Beta and Sigma - Convergence of Productivity of NUTS 2 Regions in the (EU) Member States from the CEE Region

is usually in a strong positive relationship with productivity convergence. After analysing regional data for deriving economic convergence conclusions, Cuadrado-Roura (2001) found that for the Old members the economic convergence on regional level usually stalls at some point, with "state" and "behavioural" factors being in force (setting obstacles to continuous convergence. On the other hand, Cappelen et al. (2003) find a positive impact of regional EU support for the regional convergence process. Regions with stronger regional institutions and higher level of economic development, however, are in a better position to benefit from the EU financial programs and aid (ibid.).

Stattev and Raleva (2006) carry out a review of convergence of the structure of the economy of Bulgaria and the Czech Republic towards the Eurozone averages. The dynamics of Bulgarian GDP components in expenditure and production structure are not converging with the Eurozone's ones. However, a convergence of the weights in components (i.e. the structure of GDP) can be found. In the Czech Republic a convergence with the Eurozone of the growth of the real values GDP components is revealed. In the EU member states that joined the EU in 2004 the main contributor for productivity growth for the period between 1995 and 2006 is the human capital, while foreign direct investments (FDI) and exports have lesser meaning to productivity (see Kutan and Yidit, 2009).

The biggest contributor to the economic convergence process in the CEE countries in the period 2000-2015 according to Matkowski et al. (2016) is the integration within the EU and the integration-related adjustment and modernization of institutions toward the EU standards, set by accepting countries. This is especially true for the period 20002007, while in the subsequent period (20072015) the financial crisis and the euro area 


\section{Articles}

problems stalled the convergence process for the CEE countries. It can be summarized that beta- and sigma-convergence is evident in the CEE countries (ibid.). Matkowski and Próchniak (2004) find sufficient evidence to justify beta- and sigma convergence of GDP per capita for the 1993-2003 period in the eight CEE countries from the 2004 EU expansion. When it comes to cyclical convergence, it can be observed only if the eight countries are divided into three groups, then inter group cyclical convergence exists (ibid). The view for beta convergence for the CEE countries is supported also by Dvorková (2014), while the pace of development is more heterogeneous, unable to justify the sigma convergence hypothesis. Beta -convergence of productivity by sectors for the $1975-2000$ period has been justified for the Regions of EU, while the sigmaconvergence results are not so straightforward (see Le Gallo and Dall'Erba, 2008). ${ }^{1}$

Barro and Sala-i-Martin (1991, 1992) assume a large gap between the initial economic variable and the long-term steady state of the variable in order "conditional convergence" to be justified, while Romer (1986) explains the inability of many poor economies to catch up due to insufficient human capital and/or outdated manufacturing methods. However, Sachs and Warner (1995) have more relaxed assumptions on why the catch-up process in some poor countries is not evident. The lack of proper institutions, like securing the right of ownership and the absence of working economic institutions, is the main factor for divergence (ibid.).

\section{Data and descriptive analysis}

We rely on Eurostat's datasets as a source of the dependent and explanatory variables for some of the common aggregate economic variables on a NUTS 2 regional level for the period of 2000-2016. Our study is covering 56 NUTS 2 regions of CEE member states, thus creating a panel dataset of 952 observations. The Nomenclature of Territorial Units for Statistics (NUTS) was established by Eurostat and three different type of NUTS regions can be outlined, NUTS 1, NUTS 2 and NUTS 3 regions, respectively. Each NUTS 2 region is an administrative (if possible) and territory region with an average minimum population size of 800000 and maximum of 3000000 people.

For the purpose of our analysis and for the calculation of our variables we use yearly data of the following economic variables, published by Eurostat or calculated from the authors using publicly available Eurostat's database: Gross domestic product (GDP) at current market prices by NUTS 2 regions; GDP at Purchasing power standards (PPS) by NUTS 2 regions; the Deflator of the Gross domestic product (GDP), while the deflator is calculated from seasonally and calendar adjusted GDP values and rescaled so that $2010=100$; The employment values for the NUTS2 regions.

Following variables have been calculated and analysed in the process of productivity convergence identification:

LN(GDPPE (G-n $_{n}$ )-natural logarithm of real GDP per employee in period t-n years, where " $n$ " can accept values between 0 to 16 ;

LN(GDPPE_PPS $\left.{ }_{t-n}\right)$ - natural logarithm of GDP per employee in PPS in period t-n years, where " $n$ " can accept values between 0 to 16;

The NUTS2 regions in EU countries from the region of CEE have recorded an average compound annual growth rate (CAGR) of their real GDP per employee of $2.7 \%$ per year,

\footnotetext{
${ }^{1}$ Besides the regular measures for evaluating the economic convergence, such as income, productivity, employment, Srivatsa and Lee (2012) are reviewing the convergence on the real estate market, particularly the office market. They hardly find evidence for beta-convergence of the rents and yields among the office space market, however a sigma convergence views are supported (ibid.).
} 


\section{Articles}

and $4.3 \%$ for the GDP per employee in PPS standard. Both variables are having a meaning of $0.41 \%$ and $1.65 \%$ for the NUTS 2 regions of the 15 old EU members, proving that NUTS 2 regions of the less developed members from the region of CEE are increasing productivity much faster, thus a catch-up process is evident, justifying the overall economic convergence.

Comparing the pace of economic convergence in terms of productivity, through the proxies of GDP per employee and GDP per employee in PPS terms growth rates we have calculated that the 56 regions experienced a faster convergence in terms of PPS, compared to EUR-denominated average growth rates. On average the GDP per employee rose at 2.8\% CAGR for the period $2000-2016,2.7 \%$ for the $2001-2016$ period, $1.4 \%$ for the $2011-2016$ period, while the GDP in PPS per employee rose at 4.3\% CAGR for the 2000-2016 period, $4.1 \%$ for the $2001-2016$ period, $2.2 \%$ for the $2011-2016$ period.

For the whole period under review, Romanian NUTS 2 regions have experienced the fastest growth in productivity, measured through the real GDP per employee and in PPS terms for the sixteen-year period under review. The CAGR for real GDP per employee for R012, RO11, RO22, RO42, RO31 and RO41 NUTS 2 regions is between 4.8 and $5.9 \%$ per annum, followed by BG41 region, with $4.6 \%$ per annum. The slowest productivity growth over the period under review has been recorded in Hungarian HU32, HU23, HU33, HU31 regions, the Polish PL 22 region and the Czech CZO4 region, ranging between 0.2 and $0.9 \%$ per year.

Seven Romanian NUTS 2 regions (RO32, RO12, RO11, RO22, RO42, RO31, RO41) are
Beta and Sigma - Convergence of Productivity of NUTS 2 Regions in the (EU) Member States from the CEE Region

occupying the top of the list when analysing the CAGR in PPS terms. Followed by Bulgarian BG41, Lithuanian LT00, Slovakian SK01, Latvian LV00, Polish PL11 recording CAGR between 5.4 and $6.1 \%$. On the contrary, among the worst performers with CAGR in the range $1.1-3.0 \%$ are: Romanian R021: Hungarian HU32, HU23, HU33; Polish PL22, PL42; Czech CZO4, CZO2; Bulgarian BG31, Croatian HR03.

For Bulgaria, Hungary and Slovakia the fastest CAGR have been realized by a NUTS2 region, comprised mainly of the Capital of the country. In Hungary the NUTS2 regions HU10 HU22 are experiencing the highest CAGR of GDP per employee, supporting the hypothesis that regions with higher human and/or physical capital are experiencing faster productivity and overall economic convergence, supporting the views of Romer (1986) and Kutan and Yidit (2009). Those regions were more productive at the beginning of the period.

In Bulgaria the fastest productivity convergence has been achieved by the richest and most developed economically region. The BG41 NUTS 2 region GDP per employee has grown from 10031 EUR to 20540 EUR (in real terms) from the end of year 2000 until the end of 2016. The second largest CAGR was experienced by BG34 NUTS2 region which is the second most productive region in terms of real GDP per employee, while the lowest CAGR can be seen in the poorest and less productive NUTS2 regions in Bulgaria ${ }^{2}$.

The same view can be shared for the Czech republics' CZ01 region, which has taken the lead with the largest GDP per employee at the start of the period and experiencing the fastest CAGR over the period under observation. In

\footnotetext{
${ }^{2}$ In Peshev et al. (2019) can be seen that with the catch-up process especially in Bulgaria there is a rise of inequality of financial wealth distribution (overall wealth as well). Of course, different factors are affecting the financial wealth distribution, however the convergence process in income/wealth/productivity is raising the importance of the topic since the convergence process for some individuals appear to be times faster.
} 


\section{Articles}

CZO4 which is the least productive NUTS2 region CAGR is lowest.

Similar conclusions can be drawn for Slovakia, while the cases of Poland and Romania run counter to this view. The poorer and less productive regions are experiencing higher CAGR in Poland and Romania. However, in Hungary the second most productive and richest NUTS2 (HU22) region is experiencing the highest CAGR, followed by the most developed (HU10), with less developed and less productive regions yielding lower CAGR, confirming the results and conclusions for Bulgaria, Czech Republic, Slovakia. Namely the labour productivity is the main factor for faster economic development, i.e. most productivity regions at the beginning of the period achieve the highest productivity convergence rates supporting the view for CEE countries of Szeles and Marinescu (2010).

Croatia, Latvia, Lithuania, Slovenia due the fact that usually the whole country is represented by a single or two regions NUTS2 regions are irrelevant to the observations and analysis where the NUTS2 region comprising the capital city usually is the one with the highest convergence rate. However, Romania and Poland exceed considerably the rest 9 CEE member states in terms of population, land size and NUTS 2 region count.

The openness of economies may play a role in these contradicting results. Romania and Poland can be considered less-open economies, possessing import and export to GDP ratio of 0.87 and 1.07 respectively, diverging by much from Bulgaria, Czech Republic, Hungary, Slovakia, with ratios between 1.28 to 1.94. Results of Sachs and Warner (1995) and Szeles and Marinescu (2010), suggest that openness is a key determinant of economic convergence, but in this case NUTS 2 trade openness should be analysed FDI and the quality of the human capital to absorb FDI are the main drivers in CEE member states to achieve productivity convergence according to Bijsterbosch and Kolasa (2010).

\section{Methodology and (panel) econometric investigation}

Working with a panel data for 11 countries, 56 NUTS 2 regions, respectively and a 17year period for each (incl. the beginning period of 2000 and the ending of 2016) requires a specific panel econometric technique. We have applied the ordinary least squares (OLS) method on our panel data. After performing a Hausman test for our OLS regression, the random effects option has been rejected, considering the alternative-fixed effect model use. The probability of accepting the null hypothesis of Random effects suggests that it should be rejected and the alternative hypothesis for the usage of Fixed effects should be employed instead. Therefore, our panel study is accomplished through the Fixed effects OLS panel approach.

For investigating the beta convergence, we use following equations:

$\operatorname{Ln}\left(\mathrm{GDPPE}_{\mathrm{i}, \mathrm{T}} / \mathrm{GDPPE}_{\mathrm{i}, \mathrm{t}-\mathrm{n}}\right)=$

$=\alpha+\beta \ln \left(\mathrm{GDPPE}_{\mathrm{i}, \mathrm{t}-\mathrm{n}}\right)+\mathrm{FeT}+\mathrm{u}_{\mathrm{it}}$

$(1 / \mathrm{T}) * \operatorname{Ln}\left(\mathrm{GDPPE}_{\mathrm{i}, \mathrm{T}} / \mathrm{GDPPE}_{\mathrm{i}, \mathrm{t}-\mathrm{n}}\right)=$

$=\alpha+\beta \ln \left(\mathrm{GDPPE}_{\mathrm{i}, \mathrm{t}-\mathrm{n}}\right)+\mathrm{FeT}+\mathrm{u}_{\mathrm{it}}$

Ln(GDPPE_PPS i,T $_{\text {T }} /$ GDPPE_PPS $\left._{\mathrm{i}, \mathrm{t}-\mathrm{n}}\right)=$ $=\alpha+\beta \ln \left(\mathrm{GDPPE}_{-} \mathrm{PPS}_{\mathrm{i}, \mathrm{-n}}\right)+\mathrm{FeT}+\mathrm{u}_{\mathrm{it}}$

$(1 / \mathrm{T}) * \operatorname{Ln}\left(\mathrm{GDPPE}_{\mathrm{i}, \mathrm{T}} / \mathrm{GDPPE}_{\mathrm{i},-\mathrm{n}}\right)=$

$=\alpha+\beta \ln \left(\mathrm{GDPPE}_{\mathrm{i}, \mathrm{t}-\mathrm{n}}\right)+\mathrm{FeT}+\mathrm{u}_{\mathrm{it}}$

Where:

$\ln \left(\mathrm{GDPPE}_{\mathrm{i}, \mathrm{t}-\mathrm{n}}\right)-$ is the natural logarithm of the quotient between the GDP per employee at period $\mathrm{t}-\mathrm{n}$; 


\section{Articles}

$\ln \left(\right.$ GDPPE_PPS $\left._{\mathrm{i}, \mathrm{t}-\mathrm{n}}\right)$ - is the natural logarithm of the quotient between the GDP per employee in PPS at period $t-n$;

$\operatorname{Ln}\left(\mathrm{GDPPE}_{\mathrm{i}, \mathrm{t}} / \mathrm{GDPPE}_{\mathrm{i}, \mathrm{t}-\mathrm{n}}\right)^{-}$- is the natural logarithm of the quotient between the GDP per employee at period $\mathrm{T}$ and GDP per employee at time $t-n$, i.e. the growth rate of the GDP per employee measure for the period between $t-n$ to $T$, e.g. the total growth rate (not annualized) over the period under investigation;

$(1 / \mathrm{T}) * \operatorname{Ln}\left(\mathrm{GDPPE}_{\mathrm{i}, \mathrm{t}} / \mathrm{GDPPE}_{\mathrm{i}, \mathrm{t}-\mathrm{n}}\right)$ - is the average annual growth rate of the GDPPE variable of the $i^{\text {th }}$ NUTS2 region, being itself a very good approximation for the compound annual growth rate of the GDP per employee measure for the period between $\mathrm{t}-\mathrm{n}$ to $\mathrm{T}$;

Ln(GDPPE_PPS ${ }_{\mathrm{i}, \mathrm{t}} /$ GDPPE_PPS $_{\mathrm{i}, \mathrm{t}-\mathrm{n}}$ ) is the natural logarithm of the quotient between the GDP per employee in PPS at period $\mathrm{T}$ and GDP per employee in PPS at time $t-n$, i.e. the growth rate of the GDP per employee measure for the period between $t-n$ to $\mathrm{T}$, e.g. the total growth rate (not annualized) over the period under investigation;

$(1 / T)^{*} \operatorname{Ln}\left(G D P P E_{-} P P S_{i, t} / G D P P E_{-}\right.$ PPS $_{i, t-n}$ ) - is the average annual growth rate of the GDPPE variable of the $i^{\text {th }}$ NUTS2 region, being itself a very good approximation for the compound annual growth rate of the GDP per employee in PPS measure for $\mathrm{i}^{\text {th }}$ NUTS2 region for the period between $\mathrm{t}-\mathrm{n}$ to $\mathrm{T}$;

$\mathbf{t}$ - is the notation for periods (years) and can accept values from $n$ to $T$, usually $n=16$, thus $\mathrm{t}-\mathrm{n}$ is indicative for the $2000^{\text {th }}$ year value of the variable, while $\mathrm{T}$ is usually 2016 in our study;

$\mathbf{a}$ - is a constant in the regression for the $i^{\text {th }}$ NUTS2 region;

$\boldsymbol{\beta}$-is the $\beta$-beta coefficient responsible for the $b$-convergence process, representing the relationship between the dependent and explanatory variable. A negative value of the
Beta and Sigma - Convergence of Productivity of NUTS 2 Regions in the (EU) Member States from the CEE Region

$\beta$-beta coefficient signals a beta convergence for the $i^{\text {th }}$ NUTS2 region, i.e. a catch-up process.

FeT - fixed effects term;

$\mathbf{u}_{\mathrm{it}}-$ is the error term for the $\mathrm{i}^{\text {th }}$ NUTS2 region.

\section{Results}

The application of a panel econometric investigation through the fixed effects models, as suggested from the Hausman tests, yields satisfactory result in revealing the opposite relationship between starting values of the natural logarithm of the productivity variable (Ln(GDPPE) or $\operatorname{Ln}\left(\mathrm{GDPPE}_{-}\right.$ PPS)) and the average annual growth rate $\left[(1 / \mathrm{T})^{*} \operatorname{Ln}(\right.$ GDPPEi,t/GDPPEi,t-n) or $(1 / T) * \operatorname{Ln}\left(G D P P E \_P P S i, t / G D P P E \_P P S ~ i, t-n\right]$. Individual variables' coefficient significance test and the F-test point to significant results and interactions. In the following four equations we have regressed the variables as suggested in equations 1 to 4 . It can be concluded that a beta convergence exists in the NUTS 2 regions of the CEE member states. Of course, the speed of adjustment varies for the different regions, however, it can be concluded that the catch-up process in the productivity (GDP per employee in real and PPS terms) exists. The average annual growth rate of the GDP per employee and GDP per employee in PPS is in negative relationship with the beginning of the period values of the variables, respectively the 2000 values of GDPPE and GDPPE_PPS lead to $3.7 \%$ and $5.9 \%$ decline of the average annual growth (see eq.7 and 9), i.e. the smaller the 2000 value of the variable the higher the annual growth rate. Using the Total growth of GDPPE and GDPPE_PPS supports the negative relationship with the beginning of the period values, justifying the beta-convergence. A 2000 value for GDPPE and GDPPE_PPS leads to a $55 \%$ and $87 \%$ decline respectively of the dependent variables (total growth rates), as 


\section{Articles}

can be seen in eq. 6 and 8 . All coefficient in the eq. 6 to 9 are significant at 0.001 level and all four beta-coefficients support the hypothesis that the bigger the beginning of the period value, the smaller the catch-up process. NUTS 2 regions with smaller initial base GDPPE and GDPPE_PPS grow faster in this regard.

\section{Equations represent the convergence process}

$\mathrm{LN}\left(\mathrm{GDPPE} / \mathrm{GDPPE}_{\mathrm{t}-16}\right)=$

$=5.69 * * *-0.55^{* * *} \times \mathrm{LN}\left(\mathrm{GDPPE}_{\mathrm{t}-16}\right)+\mathrm{FeT}$

Where: *, **, *** denotes statistical significance at the $10 \%, 5 \%$ and $1 \%$ levels respectively.

$R^{2}$ adj. 0.96, F-Stat 43.72,

LN(GDPPE/GDPPE $\mathrm{t}-16) / 16=$

$=0.38^{* * *}-0.037^{* * *} \times \mathrm{LN}\left(\mathrm{GDPPE}_{\mathrm{t}-16}\right)+\mathrm{FeT}$

Where: *, **, *** denotes statistical significance at the $10 \%, 5 \%$ and $1 \%$ levels
$R^{2}$ adj. 0.96, F-Stat 43.72,

LN(GDPPE_PPS/GDPPE_PPS t-16 $_{-}$)= $=9.52 * * *-0.87 * * * \times$ LN(GDPPE_PPS $\left.{ }_{\mathrm{t}-16}\right)+\mathrm{FeT}(8)$

Where: *, ${ }^{* *}, \quad * * *$ denotes statistical significance at the $10 \%, 5 \%$ and $1 \%$ levels respectively.

$R^{2}$ adj. 0.97, F-Stat 71.98,

LN(GDPPE_PPS/GDPPE_PPS $\left.\left.{ }_{\mathrm{t}-16}\right)\right) / 16=$ $0.64^{* * *}-0.059^{* * *} \times$ LN(GDPPE_PPS $\left.\mathrm{t}_{-16}\right)+\mathrm{FeT}$ (9)

Where: *, **, *** denotes statistical significance at the $10 \%, 5 \%$ and $1 \%$ levels respectively.

$R^{2}$ adj. 0.97, F-Stat 71.98,

A visual inspection of LN(GDPPE) and the average annual growth rate (LN(GDPPE_ PPS/GDPPE_PPS $\mathrm{t}_{\mathrm{t}-16} \mathrm{~J} / 16$ ) and the same interdependency in PPS terms, plotted on Figure 1 and Figure 2, suggests a negative relationship that is justified by the panel

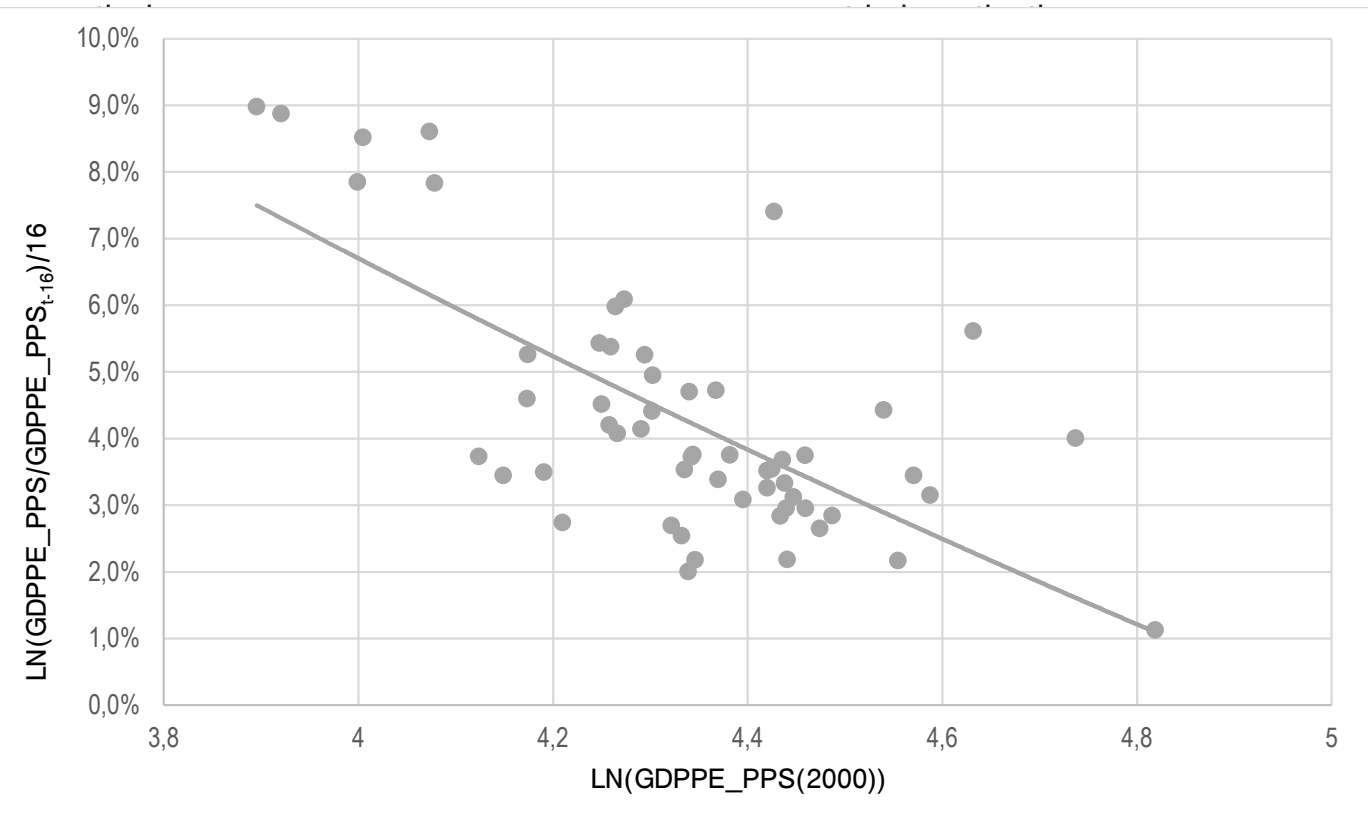

Figure 1. $L N\left(G D P P E \_P P S\right)$ - LN(GDPPE_PPS/GDPPE_PPS t-16 $\left._{1}\right) / 16$ relationship

Source: Eurostat, Own calculations. 


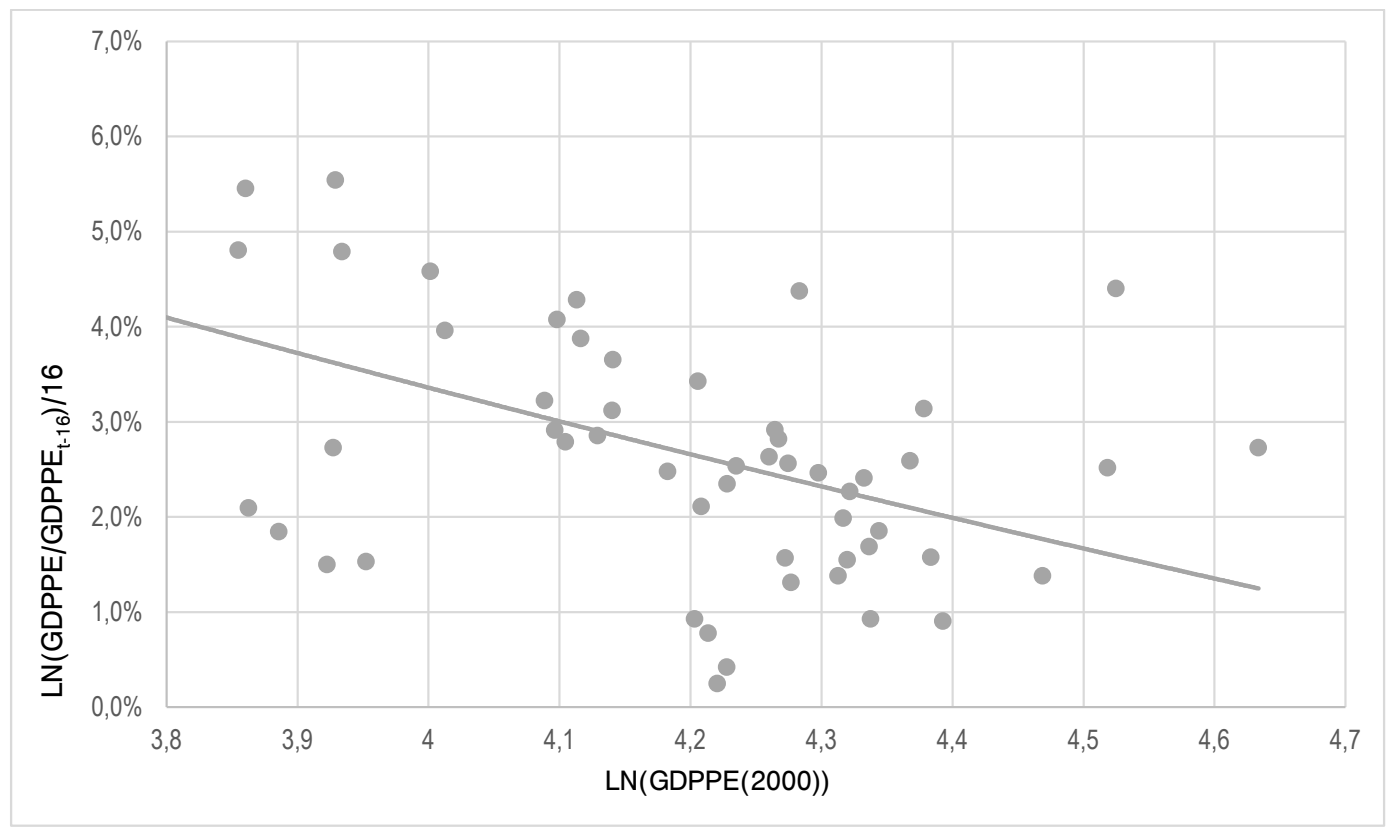

Figure 2. $L N(G D P P E)$ - $L N(G D P P E / G D P P E t-16) / 16$ relationship

Source: Eurostat, Own calculations.

\section{Sigma Convergence}

The evidence of beta convergence is not indicative of a narrowing dispersion in GDPPE and GDPPE_PPS among the NUTS2 region in the CEE member states. Therefore, the dynamics in dispersion is inspected for the presence of sigma convergence. For this purpose, we use following equation, where we regress the dispersion variable against time.

$\mathrm{CV}=\alpha+\sigma_{\mathrm{t}}+\mathrm{u}_{\mathrm{t}}$

\section{Where:}

$\mathrm{CV}$-coefficient of variation, $\mathrm{CV}=$ is calculated by dividing the standard deviation by the mean;

$\boldsymbol{\alpha}-$ is a constant in the regression for the;

$\boldsymbol{\sigma}-$ is the $\sigma$-sigma coefficient representing the relationship between the dispersion variable and time. A negative value of the coefficient reveals a decline in dispersion over time, representing a sigma convergence process;

t - period in years;

$\mathbf{u}_{\mathbf{t}}-$ is the error term for.

By using the Coefficient of variation (CV) measure as a dependent variable our analysis justifies a diminishing dispersion among the NUTS2 regions. Through visual inspection of plotted data on Figure 3 and Figure 4, the negative relationship between $\mathrm{CV}$ and time can be easily seen. It can be concluded that sigma convergence is evident in the NUTS2 regions with declining value of the Coefficient of variance. On average the CV of the Gross domestic product per employee declines by 0.005 percentage points with each year past, while the GDPPE in PPS terms declines in value by 0.008 percentage points with each year. The dispersion among the CEE NUTS2 regions has been declining in the period under the investigation. 
Articles

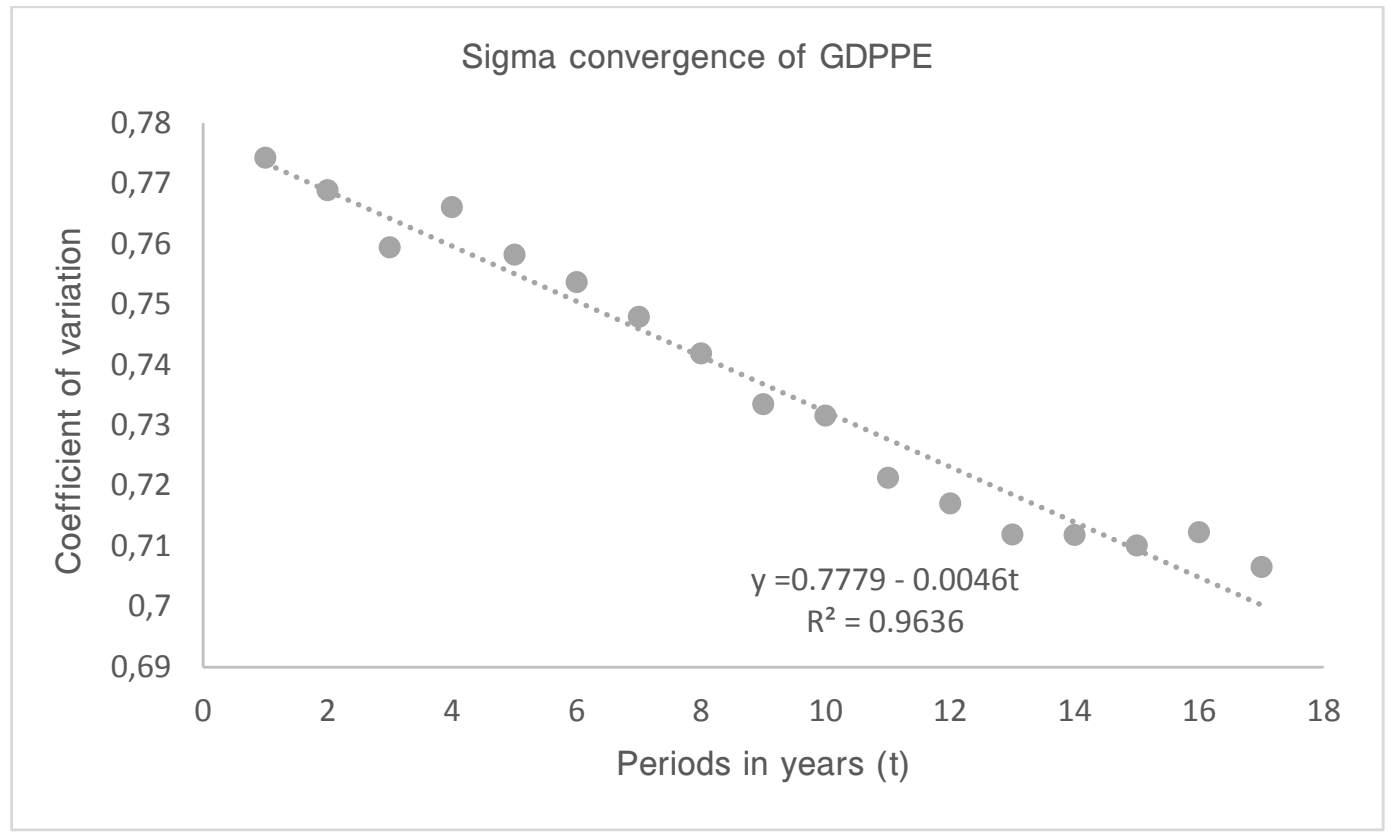

Figure 3. Coefficient of variation of GDPPE over time

Source: Own calculations based on Eurostat data.

Sigma convergence of GDPPE in PPS

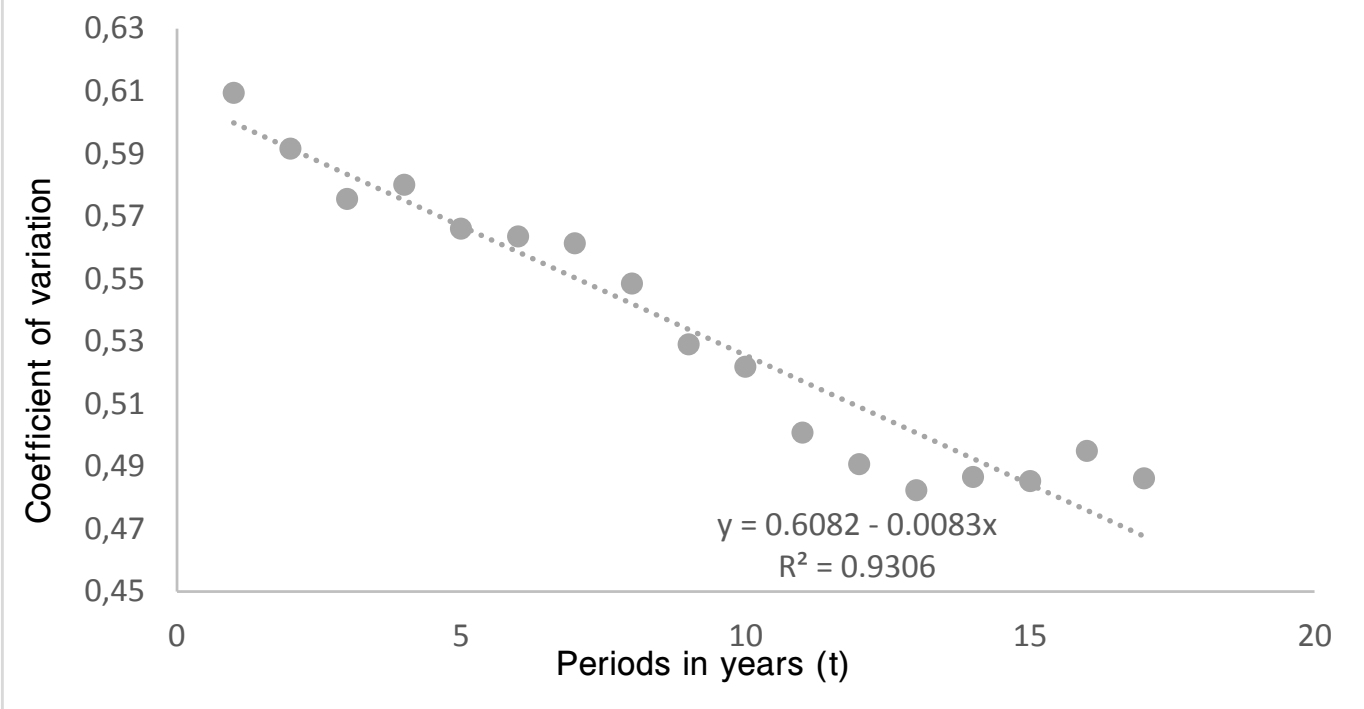

Figure 4. Coefficient of variation of GDPPE in PPS over time Source: Own calculations based on Eurostat data. 


\section{Articles}

\section{Conclusion}

In this scientific paper we analysed the productivity convergence process among the NUTS2 regions in all the CEE member states of the EU. After a descriptive analysis of the productivity dynamics in the NUTS2 regions, using the Gross domestic product per employee and Gross domestic product per employee in Purchasing powers standards for the period 2000-2016, we have performed an empirical test for the presence of beta and sigma-convergence. We have found that not only the beginning period values of variables are in negative relationship with total growth rates and annual growth rates, but also the bigger the initial value, the smaller the convergence process, i.e. a beta convergence process is justified. The dispersion among regions, approximated by the Coefficient of variation variable reveals the presence of sigma convergence, i.e. the dispersion measure declines in value over time.

Our descriptive and econometric investigation has outlined the NUTS 2 regions with the fastest growth rate of productivity, hence achieving faster productivity convergence towards the averages set by the Old EU member states. Romanian NUTS 2 have taken the lead in the process and their economic development is worth studying. FDIs, openness of the economies (NUTS 2 regions respectively), the status of the human capital and its ability to absorb FDI investments are crucial in the process, with all those factors should be considered from policymakers.

An initial critical level of human and physical capital is crucial for achieving higher productivity growth, judging by the performance of larger NUTS2 regions that usually are comprised by the capital city. This is the case in Bulgaria, Slovakia, the Czech Republic and for Hungary eventually.
Beta and Sigma - Convergence of Productivity of NUTS 2 Regions in the (EU) Member States from the CEE Region

\section{List of references:}

Barro, R. and Sala-i-Martin, X., 1991. Convergence across States and Regions, Center Discussion Paper, No. 629, Yale University, Economic Growth Center, New Haven, CT.

Barro, R. and Sala-i-Martin, X., 1992. Convergence. Journal of Political Economy, Vol 100(2), pp 223-251.

Bijsterbosch, M., \& Kolasa, M. (2010). FDI and productivity convergence in Central and Eastern Europe: an industry-level investigation. Review of World Economics, 145(4), 689-712.

Cuadrado-Roura, J. R. (2001). Regional convergence in the European Union: From hypothesis to the actual trends. The Annals of Regional Science, 35(3), 333-356.

Cappelen, A., Castellacci, F., Fagerberg, J., \& Verspagen, B. (2003). The impact of EU regional support on growth and convergence in the European Union. JCMS: Journal of Common Market Studies, 41(4), 621-644.

Le Gallo, J., \& Dall'Erba, S. (2008). Spatial and sectoral productivity convergence between European regions, 1975-2000. Papers in Regional Science, 87(4), 505-525.

Dvoroková, K. (2014). Sigma Versus Betaconvergence in EU28: do they lead to different results. Mathematical methods in finance and business administration, 88-94.

Kutan, A.M. and Yigit, T.M., 2009. European integration, productivity growth and real convergence: Evidence from the new member states. Economic Systems, 33(2), pp.127-137.

Matkowski, Z. and Próchniak, M., 2004. Real economic convergence in the EU accession countries. Prace i Materiały Instytutu Rozwoju Gospodarczego SGH, 75, pp.258-284. 
Matkowski, Z., M. Prochniak, R. Rapacki, (2016). "Real Income Convergence between Central Eastern and Western Europe: Past, Present, and Prospects", 33rd CIRET Conference on Economic Tendency Surveys and Economic Policy, Copenhagen, Denmark. Peshev,P., S. Stattev, K. Stefanova, M. Lazarova, 2019. Financial Wealth Inequality drivers in a small EU member country: An example from Bulgaria during the period 2005-2017, Economic Studies (Ikonomicheski izsledvania) journal, Issue 2, 2019.

Romer, P., 1990. Endogenous Technological Change. Journal of Political Economy, vol.98, no.5, pp. s71-s102.

Sachs, J, and Warner, A., 1995. Economic convergence and economic policies,
National Bureau of Economic Research, Vol No. w5039.

Srivatsa, R., \& Lee, S. L. (2012). European real estate market convergence. Journal of Property Investment \& Finance, 30(5), 458472.

Szeles, M.R. and Marinescu, N., 2010. Real convergence in the CEECs, euro area accession and the role of Romania. The European Journal of Comparative Economics, 7(1), p.181.

Stattev, S. and Raleva, S., 2006. Bulgarian GDP structures: convergence with the EU, South-Eastern Europe Journal of Economics, Vol 4(2).

\section{Appendix}

Table 1. GDP per employee in real and in PPS terms and CAGR

\begin{tabular}{|l|l|l|l|l|}
\hline NUTS2 Region & Ln(GDPPE_PPS(-16)) & $\begin{array}{l}\text { Ln(GDPPE_PPS/ } \\
\text { GDPPE_PPS(-16))/16 }\end{array}$ & Ln(GDPPE(-16)) & $\begin{array}{l}\text { Ln(GDPPE/ } \\
\text { GDPPE(-16))/16 }\end{array}$ \\
\hline BG31 & 9.679 & 0.030 & 9.044 & 0.015 \\
\hline BG32 & 9.599 & 0.033 & 8.969 & 0.018 \\
\hline BG33 & 9.692 & 0.034 & 9.065 & 0.019 \\
\hline BG34 & 9.675 & 0.044 & 9.070 & 0.027 \\
\hline BG41 & 9.990 & 0.053 & 9.350 & 0.039 \\
\hline BG42 & 9.543 & 0.036 & 8.917 & 0.021 \\
\hline CZ01 & 10.997 & 0.036 & 10.720 & 0.025 \\
\hline CZ02 & 10.383 & 0.026 & 10.106 & 0.016 \\
\hline CZ03 & 10.297 & 0.029 & 10.020 & 0.018 \\
\hline CZ04 & 10.235 & 0.022 & 9.958 & 0.012 \\
\hline CZ05 & 10.275 & 0.028 & 9.998 & 0.017 \\
\hline CZ06 & 10.307 & 0.032 & 10.030 & 0.022 \\
\hline CZ07 & 10.236 & 0.030 & 9.960 & 0.020 \\
\hline CZ08 & 10.273 & 0.032 & 9.997 & 0.021 \\
\hline EE00 & 9.968 & 0.049 & 9.877 & 0.023 \\
\hline HR03 & 10.291 & 0.030 & 9.858 & 0.028 \\
\hline HR04 & 10.034 & 0.046 & 9.873 & 0.027 \\
\hline HU10 & 10.685 & 0.025 & 10.354 & 0.010 \\
\hline HU21 & 10.178 & 0.029 & 9.847 & 0.014 \\
\hline & & & \\
\hline
\end{tabular}




\begin{tabular}{|c|c|c|c|c|}
\hline NUTS2 Region & Ln(GDPPE_PPS(-16)) & $\begin{array}{l}\text { Ln(GDPPE_PPS/ } \\
\text { GDPPE_PPS(-16))/16 }\end{array}$ & $\operatorname{Ln}(G D P P E(-16))$ & $\begin{array}{l}\operatorname{Ln}(G D P P E / \\
\text { GDPPE(-16))/16 }\end{array}$ \\
\hline HU22 & 10.225 & 0.035 & 9.893 & 0.020 \\
\hline HU23 & 10.069 & 0.019 & 9.738 & 0.004 \\
\hline HU31 & 10.037 & 0.023 & 9.705 & 0.008 \\
\hline HU32 & 10.076 & 0.015 & 9.745 & 0.001 \\
\hline HU33 & 10.040 & 0.022 & 9.709 & 0.008 \\
\hline LTOO & 9.942 & 0.054 & 9.564 & 0.039 \\
\hline LV00 & 9.886 & 0.049 & 9.549 & 0.036 \\
\hline PL11 & 9.894 & 0.050 & 9.503 & 0.038 \\
\hline PL12 & 10.520 & 0.042 & 10.129 & 0.030 \\
\hline PL21 & 9.923 & 0.050 & 9.532 & 0.038 \\
\hline PL22 & 10.401 & 0.029 & 10.010 & 0.017 \\
\hline PL31 & 9.705 & 0.048 & 9.314 & 0.036 \\
\hline PL32 & 9.874 & 0.041 & 9.483 & 0.029 \\
\hline PL33 & 9.940 & 0.035 & 9.549 & 0.023 \\
\hline PL34 & 9.811 & 0.043 & 9.420 & 0.031 \\
\hline PL41 & 10.198 & 0.040 & 9.807 & 0.028 \\
\hline PL42 & 10.230 & 0.028 & 9.839 & 0.016 \\
\hline PL43 & 10.056 & 0.036 & 9.665 & 0.024 \\
\hline PL51 & 10.344 & 0.034 & 9.953 & 0.022 \\
\hline PL52 & 9.966 & 0.042 & 9.575 & 0.030 \\
\hline PL61 & 10.036 & 0.037 & 9.645 & 0.025 \\
\hline PL62 & 9.955 & 0.038 & 9.564 & 0.026 \\
\hline PL63 & 10.305 & 0.028 & 9.914 & 0.016 \\
\hline $\mathrm{RO} 11$ & 9.314 & 0.074 & 8.948 & 0.045 \\
\hline R012 & 9.451 & 0.076 & 9.085 & 0.048 \\
\hline $\mathrm{RO} 21$ & 11.100 & 0.012 & 8.614 & 0.038 \\
\hline $\mathrm{RO} 22$ & 9.357 & 0.078 & 8.991 & 0.050 \\
\hline $\mathrm{RO} 31$ & 9.170 & 0.081 & 8.804 & 0.053 \\
\hline RO32 & 10.286 & 0.070 & 9.920 & 0.042 \\
\hline $\mathrm{RO} 41$ & 9.089 & 0.084 & 8.723 & 0.056 \\
\hline RO42 & 9.488 & 0.081 & 9.122 & 0.052 \\
\hline $\mathrm{SIO3}$ & 10.218 & 0.034 & 10.086 & 0.025 \\
\hline SIO4 & 10.577 & 0.033 & 10.445 & 0.024 \\
\hline SK01 & 10.728 & 0.054 & 10.440 & 0.045 \\
\hline SK02 & 10.125 & 0.037 & 9.837 & 0.027 \\
\hline SK03 & 10.072 & 0.034 & 9.784 & 0.025 \\
\hline SK04 & 10.065 & 0.032 & 9.776 & 0.022 \\
\hline
\end{tabular}

Source: Eurostat, Own calculations. 